\title{
Comparison of retrobulbar and periocular injections of lignocaine by computerised tomography
}

\author{
Auli Ropo, Pertti Nikki, Pekka Ruusuvaara, Leena Kivisaari
}

\begin{abstract}
Ten patients undergoing cataract surgery were given a local anaesthetic with lignocaine solution which was mixed with iohexol contrast medium. The location of the needle and the substance injected was determined by computerised tomography following retrobulbar or periocular anaesthesia. The retrobulbarly inserted needles were within the muscle cone, directed towards the optic foramen. The periocular needles were outside the muscle cone, tangentially along the orbital floor or pointing slightly upwards. After the retrobulbar injection the contrast medium was seen within the cone immediately after the injection and outside the cone as early as 3 minutes after the injection. With the periocular technique, however, diffusion of the anaesthetic in the opposite direction (that is, into the muscle cone) was rapid. The contrast medium was identified inside the muscle cone 2 minutes after the injection. Compression with an intraocular pressure reduction device after both of these techniques prevented exophthalmos. It is concluded that retrobulbarlike anaesthesia can also be induced by an appropriate periocular technique.
\end{abstract}

Helsinki University

Central Hospital, 00290

Helsinki, Finland

Department of

Ophthalmology

A Ropo

P Nikki

P Ruusuvaara

Department of Radiology L Kivisaari

Correspondence to:

Auli Ropo, MD, Angervotie 4

B 14, SF-00320 Helsinki,

Finland.

Accepted for publication

6 December 1990
The retrobulbar injection of lignocaine has long been used to provide analgesia and akinesia in ocular surgery. However, it carries rare but undoubted risks, for example, blindness, optic nerve penetration, scleral perforation, retrobulbar haemorrhage, meningeal irritation, and respiratory arrest. ${ }^{1}$ According to Unsöld $e t a l^{2}$ most of the complications arise from direct trauma to the orbital structures. They studied the location of the needle in a cadaver orbit using computerised tomography (CT) after retrobulbar injection and suggested an alternative position of gaze (primary gaze or slightly downward and outward). Apparently the traditional upward
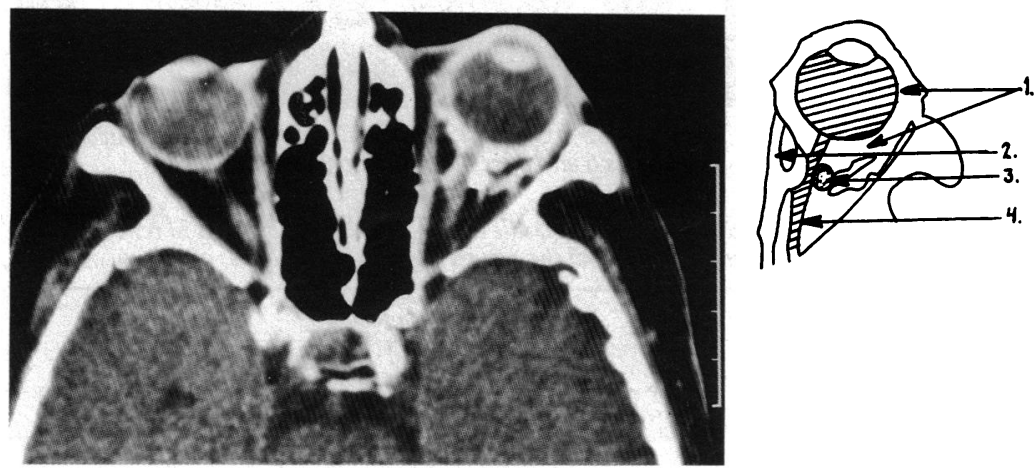

Figure 1 The needle lies in the retrobulbar space close to the optic nerve, verified by density measurements and neighbouring levels. Contrast medium is within the muscle cone at 3 min after the injection. $1=$ contrast medium, $2=$ medial rectus muscle, $3=$ needle, $4=$ optic nerve. and inward gaze rotates the essential structures into the path of the needle. ${ }^{2}$ Katsev $e t a l^{3}$ studied the path length of the retrobulbar needle and recommended that needles should be less than $31 \mathrm{~mm}$ behind the orbital rim for both retroand peribulbar anaesthesia. Recently, in a modification of the retrobulbar technique termed 'conal anaesthesia' the retrobulbar space is approached with a curved rather than a straight needle. ${ }^{4}$

In periocular anaesthesia the risk of direct injury of the delicate neural and vascular structures of the orbit is reduced because the needle lies outside the muscle cone. ${ }^{1}$

The aim of the present study was to examine the exact location of the needle together with the spread of the local anaesthetic solution in retrobulbar and periocular anaesthesia. In addition, the effect of ocular compression on postinjection exophthalmos was studied.

\section{Patients and methods}

Ten patients scheduled for elective cataract extraction gave informed consent to the study, which was approved by the Ethics Committee of the Department of Ophthalmology of Helsinki University Central Hospital. The lignocaine was administered by one of two routes: periocularly in six patients and retrobulbarly in four patients. Details of the patients are given in Tables 1 and 2.

Periocular anaesthesia was by a single inferolateral injection. The sharp needle $(25 \mathrm{~g}$, $25 \mathrm{~mm}$, Terumo, Belgium) was introduced through the skin immediately above the orbital rim along the orbital floor, care being taken to maintain the needle outside the muscle cone.

The retrobulbar anaesthesia technique was with a semisharp $35 \mathrm{~mm}$ needle (2R2, Luer Lock). An intraocular pressure reducer device (Autopressor, Storz, Heidelberg, Germany) was applied for 10 minutes at a pressure setting of 25 $\mathrm{mm} \mathrm{Hg}$ in two patients of the periocular group and one patient of the retrobulbar group. $20 \mathrm{ml}$ of $2 \%$ lignocaine solution was mixed with $0.5 \mathrm{ml}$ of water-soluble contrast medium iohexol (Omnipaque, $360 \mathrm{mg}$ iodine $/ \mathrm{ml}$, Nycomed, Norway). The volume of mixture injected by the periocular method was $4 \mathrm{ml}$ and by the retrobulbar method $3 \mathrm{ml}$.

The position of the needle was examined in two patients in each of the two techniques. The injected mixture of lignocaine and contrast medium was inspected with the aid of CT (Somatom DRH, Siemens, Germany; the scanning parameters: time $7 \mathrm{~s}, 125 \mathrm{kV}$, slice thickness $2 \mathrm{~mm}$ ). Scanning was begun immediately after the injections and was continued for 25 to 30 minutes. 


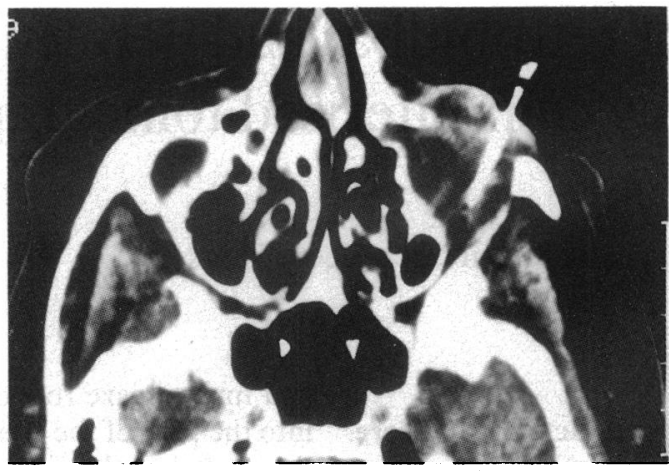

Figure 2 The periocularly inserted needle is seen outside the muscle cone tangentially along the orbital floor beneath the inferior rectus muscle. The slice is taken beneath the level of the globe.

\section{Results}

Both needles following the retrobular injections were found to be within the muscle cone. In one of the patients the needle was in close proximity to the optic nerve (Fig 1). On the other hand, when the periocular technique was used, one needle was seen tangentially along the orbital floor (Fig 2) under the inferior rectus muscle, while the second needle was orientated slightly upwards outside the muscle cone.

In the retrobulbar injections the contrast medium was seen within the muscle cone immediately after the onset of scanning (Fig 3). In all the patients in whom the retrobulbar technique was applied it was seen outside the muscle cone from 3 to $8 \mathrm{~min}$ (Table 1, Figs 4, 5). The contrast medium remained both within and outside the muscle cone during the 25-30 minutes (Fig 6). In all patients the contrast medium surrounded the optic nerve along its full length within the orbit.

As regards the periocular injections, the contrast medium was detectable outside the muscle cone in all patients from the start of the scanning. It was detectable above the superior rectus muscle within 1.5 to 3 minutes (Fig 7). In all patients, it was also evident within the muscle

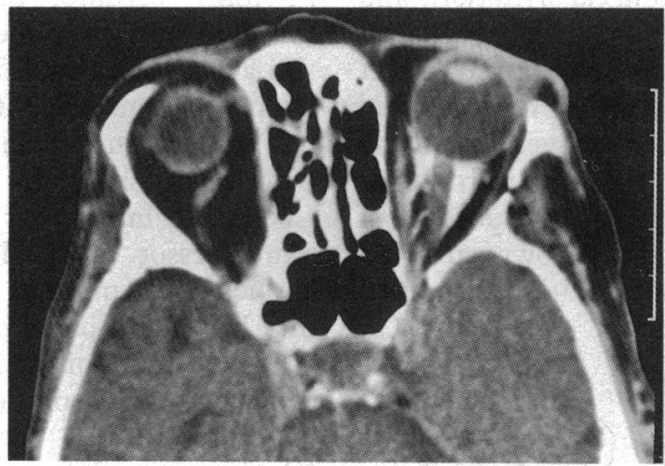

Figure 3 Retrobulbar space is filled with contrast medium 2.5 min following the retrobulbar injection.

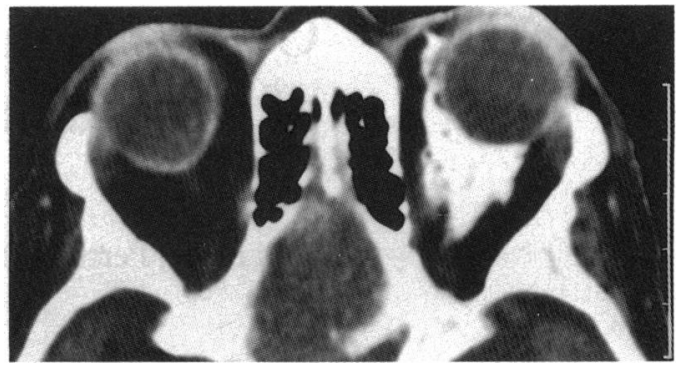

Figure 4 In addition to the retrobulbar space contrast medium is seen superiorly outside the muscle cone 3 min after the retrobulbar injection.

cone (Fig 8) occurring first there at 2-6 minutes after the injection (Table 2). Later on contrast medium was detected in the orbit so long as scanning was continued (Figs 9,10 ). The contrast medium surrounded the optic nerve along its entire route in the orbit in four patients and for a distance of $1 \mathrm{~cm}$ retrobulbarly in two patients.

Exophthalmos (of respectively 3, 4, and $5 \mathrm{~mm}$ ) occurred after the retrobulbar injection in the three patients in whom no compression was used. However, in the patient treated with compression there was no apparent exophthalmos. As regards the periocular injections, in the four patients not treated with compression no exophthalmos was detected in two, while in the remaining two patients an exophthalmos of $3 \mathrm{~mm}$ and $5 \mathrm{~mm}$ respectively occurred. In the two patients in whom compression was used following the periocular injections no exophthalmos was seen.

\section{Discussion}

In the two patients in whom the retrobulbar technique was used both needles were directed obliquely towards the optic foramen within the muscle cone. The position of the needle in close proximity to the optic nerve verifies the potential risk of penetration of this nerve or the injection of the anaesthetic solution into the subarachnoid

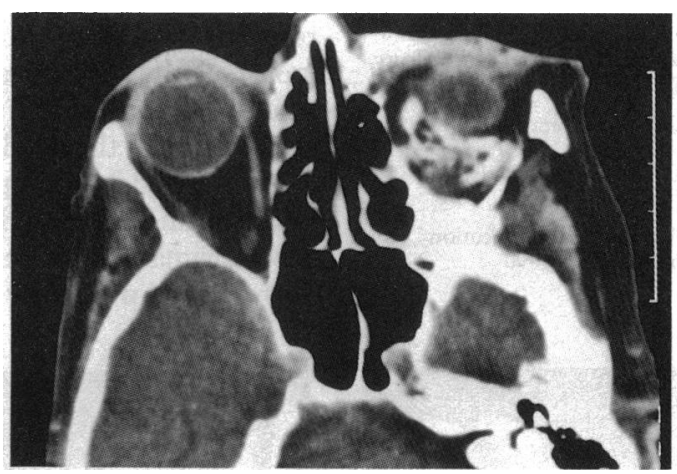

Figure 5 Contrast medium fills the intra-and extraconal spaces 6 min after the retrobulbar injection.

Table 1 Demographic data, use of ocular compression, and presence of the needle during scanning of patients in retrobulbar group. The time of detecting the contrast medium intra-or extraconally, and the occurrence of exophthalmos, are given

\begin{tabular}{|c|c|c|c|c|c|c|c|}
\hline \multirow[b]{2}{*}{ Patient } & \multirow[b]{2}{*}{ Sex } & \multirow[b]{2}{*}{$\begin{array}{l}\text { Age } \\
(y r)\end{array}$} & \multirow[b]{2}{*}{$\begin{array}{l}\text { Ocular } \\
\text { compression }\end{array}$} & \multirow[b]{2}{*}{$\begin{array}{l}\text { Needle } \\
\text { localised }\end{array}$} & \multicolumn{2}{|c|}{ Contrast medium } & \multirow[b]{2}{*}{$\begin{array}{l}\text { Exophthalmos } \\
(\mathrm{mm})\end{array}$} \\
\hline & & & & & $\begin{array}{l}\text { Intraconally } \\
\text { (min after } \\
\text { injection) }\end{array}$ & Extraconally & \\
\hline 1 & $\mathbf{F}$ & 75 & - & + & 3 & 8 & 5 \\
\hline 2 & $\mathrm{~F}$ & 70 & - & + & $3 \cdot 5$ & 3 & 3 \\
\hline 3 & $\mathbf{F}$ & 81 & + & - & $1 \cdot 5$ & 6 & 0 \\
\hline 4 & F & 61 & - & - & 3 & 3 & 4 \\
\hline
\end{tabular}


Figure 6 At 24 min after the retrobulbar injection contrast medium is still obvious in the orbit.

Figure 7 Contrast medium is seen extraconally above the superior rectus muscle 3 min after the inferolateral periocular injection.

Figure 8 At 4 min after the periocular injection contrast medium is both intra-and extraconaly.

Figure 9 At 8 min after the periocular injection contrast medium fills the orbit.
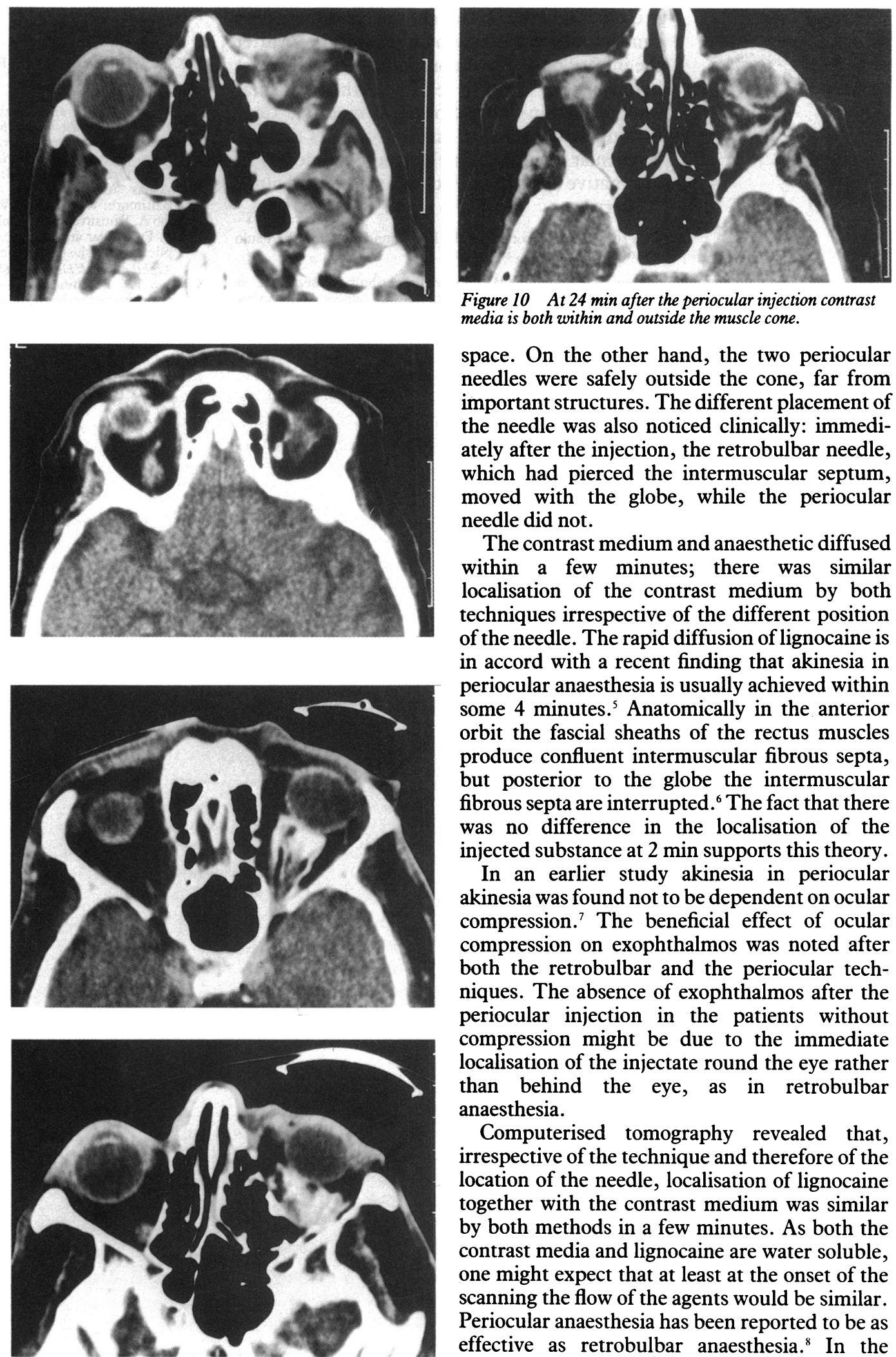

Figure 10 At 24 min after the periocular injection contrast media is both within and outside the muscle cone.

space. On the other hand, the two periocular needles were safely outside the cone, far from important structures. The different placement of the needle was also noticed clinically: immediately after the injection, the retrobulbar needle, which had pierced the intermuscular septum, moved with the globe, while the periocular needle did not.

The contrast medium and anaesthetic diffused within a few minutes; there was similar localisation of the contrast medium by both techniques irrespective of the different position of the needle. The rapid diffusion of lignocaine is in accord with a recent finding that akinesia in periocular anaesthesia is usually achieved within some 4 minutes. ${ }^{5}$ Anatomically in the anterior orbit the fascial sheaths of the rectus muscles produce confluent intermuscular fibrous septa, but posterior to the globe the intermuscular fibrous septa are interrupted. ${ }^{6}$ The fact that there was no difference in the localisation of the injected substance at $2 \mathrm{~min}$ supports this theory.

In an earlier study akinesia in periocular akinesia was found not to be dependent on ocular compression. ' The beneficial effect of ocular compression on exophthalmos was noted after both the retrobulbar and the periocular techniques. The absence of exophthalmos after the periocular injection in the patients without compression might be due to the immediate localisation of the injectate round the eye rather than behind the eye, as in retrobulbar anaesthesia.

Computerised tomography revealed that, irrespective of the technique and therefore of the location of the needle, localisation of lignocaine together with the contrast medium was similar by both methods in a few minutes. As both the contrast media and lignocaine are water soluble, one might expect that at least at the onset of the scanning the flow of the agents would be similar. Periocular anaesthesia has been reported to be as effective as retrobulbar anaesthesia. ${ }^{8}$ In the

Table 2 Demographic data, use of ocular compression, and presence of the needle during scanning of patients in periocular group. The time of detecting the contrast medium intra-or extraconally, and the occurrence of exophthalmos, are given

\begin{tabular}{|c|c|c|c|c|c|c|c|}
\hline \multirow[b]{2}{*}{ Patient } & \multirow[b]{2}{*}{ Sex } & \multirow[b]{2}{*}{$\begin{array}{l}\text { Age } \\
\text { (yr) }\end{array}$} & \multirow[b]{2}{*}{$\begin{array}{l}\text { Ocular } \\
\text { compression }\end{array}$} & \multirow[b]{2}{*}{$\begin{array}{l}\text { Needle } \\
\text { localised }\end{array}$} & \multicolumn{2}{|c|}{ Contrast medium } & \multirow[b]{2}{*}{$\begin{array}{l}\text { Exophthalmo } \\
(\mathrm{mm})\end{array}$} \\
\hline & & & & & $\begin{array}{l}\text { Intracomally } \\
\text { (min after } \\
\text { injection) }\end{array}$ & Extraconally & \\
\hline $\begin{array}{l}1 \\
2 \\
3 \\
4 \\
5 \\
6\end{array}$ & $\begin{array}{l}F \\
F \\
F \\
M \\
M \\
M\end{array}$ & $\begin{array}{l}77 \\
83 \\
70 \\
88 \\
72 \\
39\end{array}$ & $\begin{array}{l}- \\
- \\
- \\
+ \\
- \\
+\end{array}$ & $\begin{array}{l}- \\
\overline{+} \\
- \\
+ \\
+\end{array}$ & $\begin{array}{l}6 \\
2 \\
4 \\
5 \\
4 \\
3\end{array}$ & $\begin{array}{l}6 \\
2 \\
3 \\
5 \\
1 \\
2\end{array}$ & $\begin{array}{l}3 \\
5 \\
0 \\
0 \\
0 \\
0\end{array}$ \\
\hline
\end{tabular}


present study the location of the anaesthetic was similar by both methods as early as 3-4 min after the injection. The position of the needle, at least in our hands, seems to be safer in the periocular rather than in the retrobulbar method. Confirming earlier studies, this study shows that the periocular technique can be recommended as an alternative anaesthetic technique for ophthalmic surgery.

This study was supported by the Eye Foundation and the Paulo Foundation, Helsinki, Finland.

1 Davis DB, Mandel MR. Posterior peribulbar anesthesia: an alternative to retrobulbar anesthesia. Implants Ophthalmol 1986; 2: 154-6.
2 Unsöld R, Stanley JA, De Groot J. The CT-topography of retrobulbar anesthesia. Graefes Arch Clin Exp Ophthalmo 1981; 217: 125-36.

3 Katsev DA, Drews RC, Rose BT. An anatomic study of retrobulbar needle path length. Ophthalmology 1989; 96 . $1221-4$.

4 Buttery B. Conal anaesthesia: a new approach to retrobulbar anaesthesia. Aust NZ F Ophthalmol 1989; 17: 63-9.

5 Davis PL, O'Connor P. Peribulbar block for cataract surgery: a prospective double-blind study of two local anaesthetics. a prospective double-blind study

6 Doxanas MT, Anderson RL. Clinical orbital anatomy. Baltimore: Williams and Wilkins, 1984: 108-15.

7 Ropo A, Ruusuvaara P, Paloheimo M, Maunuksela E-L, Nikki P. Periocular anaesthesia: technique, effectiveness and complications with special reference to postoperative ptosis. Acto Ophthalmol (Kbh) 1990; 68: 728-32.

8 Weiss JL, Deichman CB. A comparison of retrobulbar and periocular anesthesia for cataract surgery. Arch Ophthalmol 1989; 107: 96-8. 